\title{
Implicações produtivas de pastejo sob alta severidade em azevém anual manejados com lotação intermitente
}

Denise Adelaide Gomes Elejalde ${ }^{1}$, André Brugnara Soares ${ }^{2}$, Angélica Caroline Zatta ${ }^{3}$, Igor Kieling Severo ${ }^{3}$, Daniel Schmittt e Felipe Luiz Chiamulera Deifeld ${ }^{3}$

Resumo - O manejo de desfolha possui como um dos principais objetivos o rebrote vigoroso após o rebaixamento, uma vez que a área foliar remanescente possui alta correlação com o potencial de rebrote dos pastos. Desta forma, o objetivo do presente trabalho foi avaliar o efeito de intervenções pontuais de alta severidade $(70 \%)$ sobre características produtivas de pastos de azevém anual manejados sob desfolhações intermitentes. $O$ experimento foi conduzido na área experimental da Universidade Tecnológica Federal do Paraná. Os tratamentos consistiram de quatro estratégias de desfolha a partir de uma única altura de entrada $(20 \mathrm{~cm})$ : severidade constante de $40 \%$; severidade de $40 \%$ com intervenções pontuais de $70 \%$ no segundo corte; severidade de $40 \%$ com intervenções pontuais de $70 \%$ no quarto corte; e severidades de $40 \%$ e $70 \%$ intercaladas. Os tratamentos foram aplicados em delineamento inteiramente casualizado com três repetições, totalizando 12 unidades experimentais. Foram avaliadas as variáveis de interceptação de radiação solar, produção de forragem e características morfogênicas (taxa de aparecimento foliar, filocrono, taxa de alongamento foliar e taxa de senescência foliar). A interceptação de radiação solar pré desfolha não diferiu entre os tratamentos, apenas na situação pós desfolha. Para as características morfogênicas os tratamentos com alta severidade de desfolha, apresentaram os maiores valores morfogênicos. A produção de forragem não diferiu entre os tratamentos. Dentro das condições aplicadas no presente estudo (i.e. altura précorte), intervenções pontuais de alta severidade (70\%) não afetam a capacidade produtiva do azevém anual.

Termos de indexação: Ecofisiologia vegetal; Plantas forrageiras; Manejo de pastagens.

\section{Productive implications in grazing under high severity defoliations in Italian ryegrass managed under intermittent stocking method}

\begin{abstract}
Grazing management has as one of the main objectives the vigorous regrowth, since the remaining leaf area has a high correlation with the regrowth potential of pastures. Thus, the objective of the present work was to evaluate the effect of high severity punctual interventions (70\%) on productive characteristics of Italian ryegrass pastures managed under intermittent stocking method. The experiment was conducted in the experimental area of the Federal Technological University of Paraná. The treatments consisted of four defoliation strategies from a single entry height $(20 \mathrm{~cm})$ : constant severity $40 \%$; severity of $40 \%$ with punctual interventions of $70 \%$ in the second cut; severity of $40 \%$ with punctual interventions of $70 \%$ in the fourth cut; and severities of $40 \%$ and $70 \%$ interspersed. The treatments were applied in a completely randomized design with three replications, totaling 12 experimental units. It was evaluated: solar radiation interception, forage production and morphogenic characteristics (leaf appearance rate, phyllochron, leaf elongation rate and leaf senescence rate). The pre-defoliation solar radiation interception did not differ between treatments, only in the post-defoliation situation. For morphogenic characteristics, treatments with high defoliation severity presented the highest values. Forage production did not differ between treatments. Within the conditions applied in the present study (i.e. pre-cut height), punctual interventions of high severity $(70 \%)$ do not affect the productive capacity of Italian ryegrass.
\end{abstract}

Index terms: Plant ecophysiology; Forage plants; Grazing management.

\section{Introdução}

O uso das pastagens na pecuária encontra alguns impasses quanto à escoIha do manejo adequado para cada situação e envolve um conjunto de fatores que possibilitam a obtenção de resultados satisfatórios. Apesar de parecer simples, qualquer decisão equivocada pode penalizar o potencial de produção da cultura. Costa et al. (2021) discutem quais estratégias de manejo devem ser adotadas a partir de um contexto multidisciplinar, analisando de forma sistêmica e integrada as respostas de cada componente da interface solo-plantaanimal.

O manejo correto da pastagem, as- 
sociado ao ajuste da intensidade de pastejo, determina a persistência da pastagem e o nível de produção por animal e por área (EUCLIDES et al., 2019). O manejo de desfolha possui como um dos principais fatores a rebrota vigorosa após utilização ou rebaixamento do pasto (MEZZALIRA et al., 2014), uma vez que a área foliar remanescente possui alta correlação com o potencial de rebrotação dos pastos. Este processo ocorre em função da relação linear e positiva entre o Índice de Área Foliar (IAF) e a produção de forragem, devido à maior capacidade fotossintética remanescente no vigor da rebrotação. No caso da cultura do azevém, apesar de ela suportar elevadas cargas e apresentar bom rebrote devido a sua plasticidade, o manejo do pastejo não pode exceder a sua capacidade de rebrotação, pois os tecidos foliares estão sujeitos aos eventos de desfolhação, cuja frequência e severidade podem afetar a taxa de produção de novos tecidos.

Estudos sobre a ecofisiologia das plantas forrageiras e a ecologia do pastejo são ferramentas importantes de manejo que devem ser incorporados nas avaliações das forrageiras e podem auxiliar no entendimento da relação entre solo-planta-animal-meio do sistema (COSTA et al., 2020). Logo, o presente trabalho avaliou o efeito de intervenções pontuais de alta severidade (70\%) sobre as características produtivas de pastos de azevém anual manejados sob desfolhações intermitentes

\section{Material e métodos}

O estudo foi desenvolvido na área experimental da Universidade Tecnológica Federal do Paraná, Pato Branco, PR. O delineamento experimental utilizado foi inteiramente casualizado, com três repetições. Os tratamentos consistiram de quatro estratégias de desfolha a partir de uma única altura de entrada $(20 \mathrm{~cm})$, sendo: severidade constante de $40 \%$ (40); severidade de $40 \%$ com intervenções pontuais de $70 \%$ no segundo (70I); severidade de $40 \%$ com intervenções pontuais de $70 \%$ no quarto corte (70F); e severidades de $40 \%$ e $70 \%$ in- tercaladas (40/70). A escolha da altura em pré-corte foi baseada no trabalho de Santos et al. (2016), uma vez que a partir de $18-20 \mathrm{~cm}$ poderia haver significativos incrementos nas taxas de alongamento de colmos.

A densidade de semeadura utilizada foi $25 \mathrm{~kg} \mathrm{ha}^{-1}$ de sementes viáveis com plantio realizado em linha, com espaçamento de $0,17 \mathrm{~m}$ entre linhas. Foram utilizadas 12 unidades experimentais com área útil de $2,25 \mathrm{~m}^{2}$ cada, semeadas no dia 08/05/2017 com azevém anual (Lolium multiflorum Lam.) cv. Bar $\mathrm{HQ}$, caracterizado por ser tetraploide da tipologia Westworld (Westerwoldicum). De acordo com a análise de solo, o solo apresentava na camada de $0-20 \mathrm{~cm}$, as seguintes características químicas: $\mathrm{pH}$ (Índice SMP) $=6,0 ; \mathrm{MO}=2,7 \%$;

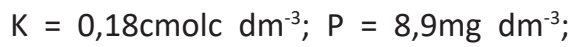

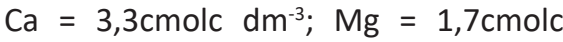
$\mathrm{dm}^{-3} ; \quad \mathrm{H}+\mathrm{Al}=4,9 \mathrm{cmolc} \mathrm{dm}^{-3} ;$

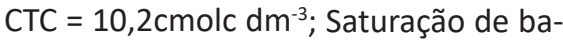
ses $=51,1 \%$; Argila $=>60 \%$. Com base nesses valores, foram realizadas adubações de correção a lanço para gramíneas de estação fria (plantas forrageiras) de acordo com o Manual de Adubação e Calagem para os Estados do Rio Grande do Sul e de Santa Catarina, Brasil (Comissão de química e fertilidade do solo - RS/SC, 2004). As adubações de base fosfatada e potássica foram aplicadas na quantidade de $55 \mathrm{~kg} \mathrm{ha}^{-1} \mathrm{P}_{2} \mathrm{O}_{5}$ e $72 \mathrm{~kg} \mathrm{ha}^{-1}$ $\mathrm{K}_{2} \mathrm{O}$. A adubação nitrogenada foi parcelada em três aplicações, totalizando $300 \mathrm{~kg} \mathrm{ha}^{-1}$ de $\mathrm{N}$, quantidade menor que o indicado para o cultivar Bar HQ pela empresa comercializadora das sementes $\left(350 \mathrm{~kg} \mathrm{ha}^{-1}\right.$ de adubo nitrogenado + $150 \mathrm{~kg} \mathrm{ha}^{-1}$ de adubo potássico).

Os pastos foram manejados por meio de cortes mecânicos realizados com uso de roçadeira sempre que atingiam $20 \mathrm{~cm}$ de altura. No dia 19/07/2017 foram submetidos à primeira desfolhação de $40 \%$, sendo o período experimental finalizado em 14/10/2017, quando os pastos não apresentavam sinais de crescimento. A altura do dossel foi monitorada duas vezes por semana em 20 pontos por unidade experimental com o auxílio de um bastão graduado em centímetros.
A avaliação de interceptação de radiação solar (IRS) foi realizada quando os pastos atingiam a altura de précorte $(20 \mathrm{~cm})$ e imediatamente após o rebaixamento. Foram realizadas cinco leituras de radiação solar por parcela com auxílio de ceptômetro de barra linear (modelo LP-80 Decagon Devices, USA). Para tanto, o aparelho era inserido sobre o dossel e posteriormente, abaixo do dossel e perpendicularmente às linhas de semeadura. Os valores de IRS foram obtidos a partir da diferença entre as leituras (acima e abaixo do dossel).

Quando os pastos atingiram a altura pré-corte de $20 \mathrm{~cm}$ foi realizada a coleta de forragem de forma estratificada em estrato superior $(50 \%$ da altura superior) e inferior (remanescente) através de um quadro de $0,5 \mathrm{~m}^{2}$ e $0,01 \mathrm{~m}^{2}$, respectivamente. Foram coletadas uma amostra do estrato superior e duas do inferior. Metade das amostras foi pesada e seca em estufa de circulação de ar forçado a $55^{\circ} \mathrm{C}$ por 72 horas e destinadas à determinação da massa de forragem expressa em kg de MS ha-1. A partir do somatório das massas de forragem foi quantificada a produção total de matéria seca (PTMS).

Para as avaliações morfogênicas e o fluxo de tecidos foi realizada a metodologia de "perfilhos marcados", descrita por CARRÈRE et al. (1997), sendo marcados 15 perfilhos por unidade experimental, totalizando 180 perfilhos. Foi determinada a Taxa de Aparecimento de Folhas (TApF), Filocrono (FIL), Taxa de Alongamento de Lâminas Foliares (TALF) e Taxa de Senescência Foliar (TSF) de acordo com metodologia de MARTI$\mathrm{NI}$ et al. (2019). Para a Duração de Vida da Folha (DVF - dias), considerou-se o tempo entre o aparecimento do ápice foliar e o primeiro sinal de senescência da lâmina, ou seja, o tempo em que a folha permaneceu verde (OLIVEIRA, 2007).

Para as avaliações das características estruturais foi medido o Comprimento Médio das Lâminas Foliares (CLF $-\mathrm{cm}$ / folha) com régua milimétrica e o Número de Folhas Vivas por perfilho (NFV). Para obtenção do NFV foi contabilizado 
o número médio de folhas em expansão expandidas e em senescência de cada perfilho, desconsiderando-se as folhas em que o processo de senescência havia ultrapassado $50 \%$ do limbo foliar. $\mathrm{NFV}=(\mathrm{LFeE}+\mathrm{LFE}+\mathrm{LFS}) / \mathrm{n}$ - perfilhos em avaliação, onde: LFeE - Lâminas Foliares em Expansão; LFE - Lâminas Foliares Expandidas e LFS - Lâminas Foliares Senescentes.

As avaliações de densidade populacional de perfilhos (DPP, $n^{\circ}$ de perfilhos $\mathrm{m}^{-2}$ ) foram realizadas em pré-desfolha através da contagem direta de perfilhos em três pontos por unidade experimental em quadros de $0,01 \mathrm{~m}^{2}$. O Índice da Área Foliar (IAF) foi determinado em pré-corte através de coletas aleatórias em cada unidade experimental de 20 perfilhos, dos quais foram destacadas as lâminas foliares e integradas no Integrador de Área Foliar (LI-COR LI3100C). Posteriormente, as lâminas medidas foram pesadas, obtendo-se o peso específico. Por meio da avaliação de separação estrutural (lâmina, colmo e material morto), o quociente entre a área foliar e a massa seca de lâminas por perfilho resultou na área foliar específica $\left(\mathrm{cm}^{2} \mathrm{~g}^{-1}\right)$. $\mathrm{IAF}=\mathrm{DDPAf}$, onde: $\mathrm{Af}$ = área foliar média por perfilho $\left(\mathrm{em} \mathrm{m}^{2}\right)$.

Após atendidos os pressupostos de normalidade e homogeneidade de variâncias, os dados foram submetidos à análise de variância através do procedimento PROC GLM do SAS. As médias foram comparadas pelo teste " $\mathrm{t}$ " de Student ao nível de significância de 5\% ( $P \leq 0,05)$.

\section{Resultados e discussão}

Na Tabela 1 são apresentadas a Produção de Matéria Seca Total (PMST, kg MS/ha) e a Interceptação de Radiação Solar (IRS) dos estratos superiores e inferiores de pasto submetido a diferentes manejos de desfolha. Para a Interceptação de Radiação Solar (IRS) observou-se diferença significativa entre os tratamentos no pós-desfolha. Dessa forma, pastos mantidos a uma severidade de desfolha constante de $40 \%$ apresentaram os maiores valores de IRS, enquanto no manejo intercalado (40/70) os

Tabela 1. Produção de matéria seca total (PMST, kg MS/ha) e interceptação de radiação solar (IRS) dos estratos superiores e inferiores de pasto submetido a diferentes manejos de desfolha

Table 1. Total dry matter production (TDMP, $\mathrm{kg} \mathrm{DM} \mathrm{ha}^{-1}$ ) and solar radiation interception (SRI) from the upper and lower strata of pasture under different defoliation management

\begin{tabular}{lcccccc}
\hline & \multicolumn{9}{c}{ Tratamentos } & P-value & EPM \\
\cline { 2 - 5 } Variáveis & 40 & $40 / 70$ & $70 \mathrm{~F}$ & 701 & & \\
\hline \%IRS pré & 92 & 91 & 90 & 92 & 0,1109 & 0,911 \\
\%IRS pós & $67 \mathrm{~A}$ & $54 \mathrm{C}$ & $58 \mathrm{~B}$ & $60 \mathrm{~B}$ & 0,0434 & 0,031 \\
PMST & 6470 & 6144 & 6376 & 5871 & 0,4687 & 300 \\
\hline
\end{tabular}

\%IRS pré - \% interceptação de radiação solar pré desfolha; IRS pós - \% interceptação de radiação solar pós-desfolha. "Médias seguidas da mesma letra maiúscula na linha diferem pelo teste " $\mathrm{t}$ " de Student $(P<0,05)$. EPM - erro padrão da média.

menores valores e os tratamentos 701 e 70F tiveram IRS iguais e intermediários. A IRS em pré-desfolha não diferiu entre os tratamentos ( $P>0,005)$. Amaral et al. (2012), trabalhando com azevém comum manejado sob lotação intermitente com quatro tratamentos com combinação de dois pré-pastejos (15 e $25 \mathrm{~cm}$ ) e duas alturas de pasto pós-pastejo (5 e $10 \mathrm{~cm})$, reportaram valores de IRS próximos a 95\% (ponto crítico) para pastos manejados na altura de pré-pastejo de $25 \mathrm{~cm}$ e para pastos de $15 \mathrm{~cm}$ apresentaram 92\% de IRS. Pastos manejados abaixo do valor crítico de IRS, mas com desfolhações lenientes, podem apresentar potenciais produtivos equivalentes (SBRISSIA et al., 2018), sendo possível que pastos de azevém anual possam ser manejados com alturas de pré-corte entre 15 e $25 \mathrm{~cm}$, sem que haja o comprometimento do potencial produtivo.

Não houve diferença $(P>0,05)$ entre os tratamentos para a variável produção de matéria seca total (Tabela 1). Embora não significativa, observa-se semelhança nos valores de PMST para os tratamentos 40 e 70F, provavelmente porque no tratamento 70F a intervenção ocorreu ao final do período experimental não afetando negativamente a PMST. Segundo Mezzalira et al. (2014), pastos rebaixados em mais de $40 \%$ comprometem a velocidade de ingestão de forragem. Schmitt (2016) corroborou parte desses resultados, uma vez que demonstrou que o consumo diário de forragem é linearmente reduzido com o aumento da severidade de desfolha. Esses dados evidenciam que, pelo menos no curto prazo, pode haver uma certa "homeostasia" entre os tratamentos de modo a não prejudicar a quantidade de forragem colhida. Todavia, é provável que o animal em pastejo seja penalizado com tais práticas.

Na Tabela 2 são apresentadas as características morfogênicas de pasto submetido a diferentes manejos de desfolha. São elas: TApF - Taxa de Aparecimento Foliar (folha/perfilho/dia); FIL - Filocrono (dias); TAIF - Taxa de Alongamento Foliar (cm/perfilho/dia) e TSF - Taxa de Senescência Foliar (cm/ perfilho/dia). Observou-se maior taxa de aparecimento e alongamento foliar no tratamento mantido com $40 \%$ de severidade. Resultado contrário à literatura, que diz que TApF e TAIF apresentam correlação negativa, sendo desta forma inversamente proporcionais. Quanto maior a taxa de aparecimento foliar, menor o tempo para o alongamento (SBRISSIA \& DA SILVA, 2008). Entretanto, de forma geral, Chaves et al. (2018) afirmam que a TApF pode ser influenciada pela TAIF. A TApF possui um papel determinante nas características estruturais do dossel, uma vez que interfere diretamente no tamanho da folha, na DPP e no número de folhas por perfilho (LEMAIRE \& CHAPMAN, 1996).

A morfogênese de uma gramínea durante seu crescimento vegetativo é caracterizada por três fatores, segundo CHAPMAN \& LEMAIRE (1993): a taxa de aparecimento, taxa de alongamento e a longevidade das folhas. Portanto, a produtividade das gramíneas forrageiras decorre da contínua emissão de folhas e perfilhos. Para a variável filocrono $(P<0,05)$ o tratamento 70F apresentou 
Tabela 2. Características morfogênicas de pasto submetido a diferentes manejos de desfolha

Table 2. Morphogenetic characteristics of pasture under different defoliation management

\begin{tabular}{|c|c|c|c|c|c|c|}
\hline \multirow{2}{*}{ Variáveis } & \multicolumn{4}{|c|}{ Tratamentos } & \multirow{2}{*}{ P-value ${ }^{\#}$} & \multirow{2}{*}{ EPM } \\
\hline & 40 & $40 / 70$ & $70 \mathrm{~F}$ & 701 & & \\
\hline TApF & $0,0085 \mathrm{~A}$ & $0,0074 \mathrm{~B}$ & $0,0072 \mathrm{~B}$ & $0,0076 \mathrm{AB}$ & 0,0493 & 0,0003 \\
\hline FIL & $11,00 \mathrm{~B}$ & $12,80 \mathrm{~A}$ & $13,20 \mathrm{~A}$ & $12,60 \mathrm{~A}$ & 0,0098 & 0,45 \\
\hline TAIF & $2,60 \mathrm{~A}$ & $2,20 \mathrm{~B}$ & $2,40 A B$ & $2,30 \mathrm{~B}$ & 0,0245 & 0,09 \\
\hline TSF & $0,50 \mathrm{~A}$ & $0,30 \mathrm{~B}$ & $0,37 \mathrm{~B}$ & $0,40 A B$ & 0,0180 & 0,94 \\
\hline DVF & 47,5 & 43,4 & 46,7 & 48,1 & 0,2980 & 1,8 \\
\hline
\end{tabular}

TApF - Taxa de Aparecimento Foliar (folha/perfilho/dia); FIL - Filocrono (dias); TAlF - Taxa de Alongamento Foliar (cm/perfilho/dia); TSF - Taxa de Senescência Foliar (cm/perfilho/dia); DVF Duração de Vida da Folha (dias). "Médias seguidas da mesma letra maiúscula na linha diferem pelo teste " $\mathrm{t}$ " de Student $(\mathrm{P}<0,05)$.

média superior, não diferindo do tratamento 40/70 e 70I. O filocrono é o tempo necessário para o aparecimento de duas folhas consecutivas, sendo resultante do inverso da TApF. Neste trabalho foram necessários em média 11 dias para aparecimento de uma lâmina foliar no tratamento 40 e cerca de 13 dias para os demais tratamentos. Pena et al. (2009) e Sbrissia \& Da Silva (2008) observaram relação inversa entre filocrono e TAIF, avaliando capim Tanzânia e Marandu, respectivamente. Neste trabalho não foi observada essa relação inversa. Pena et al. (2009) conclui que o intervalo entre cortes no capim Tanzânia não deve exceder o tempo necessário para o aparecimento de duas a três folhas por perfilho e que tanto $o$ intervalo quanto à altura de corte podem influenciar o acúmulo e a composição morfológica da forragem produzida.

As maiores taxas de alongamento foliar e de senescência ocorreram no tratamento 40 , embora não tenham diferido do tratamento $70 \mathrm{~F}$ (Tabela 2), resultado que se deve ao maior índice de área foliar (Tabela 3). Para taxa de senescência, o tratamento 40 apresentou os maiores valores, mas não diferiu do tratamento 70I. A taxa de senescência responde diretamente a mudanças na massa de forragem em função da desfolha. As respostas encontradas baseiam-se no balanço entre o fluxo de crescimento do pasto, ou seja, ao mesmo tempo que surgem novas lâminas foliares e o pasto cresce mais, também ocorrem a morte de folhas maduras. A senescência foliar reduz a quantidade de forragem de qualidade, pois as porções verdes da planta são as mais nutritivas para a dieta animal (MARTINI et al., 2019). Avaliando o fluxo de tecidos de azevém sob manejo de desfolha, Cauduro et al. (2007) observaram balanço positivo (4,7kg de MS/ha/dia) em baixa intensidade de pastejo em lotação intermitente, onde o fluxo de crescimento superou o de senescência e consumo, enquanto a intensidade de pastejo média demonstrou balanço negativo (-15,9kg de MS ha-1 dia $\left.^{-1}\right)$.

Na Tabela 3 são apresentadas as características estruturais do pasto submetido a diferentes manejos de desfoIha. São elas: CLF - Comprimento Médio das Lâminas Foliares (cm/folha); NFV Número de Folhas Vivas por perfilho; DPP - Densidade Populacional de PerfiIhos (perfilhos $\mathrm{m}^{-2}$ ); IAF - Índice de Área Foliar. O comprimento médio das lâminas foliares e a densidade populacional de perfilhos não diferiram entre os tratamentos $(P>0,05)$. O comportamento para DPP está atrelado à ausência de decapitação dos meristemas apicais dos perfilhos remanescentes (baseado em observações visuais) e pela pouca alteração do ambiente luminoso, uma vez que os pastos foram semeados em linha. De fato, esperavam-se diferenças nas estratégias de maiores severidades de desfolhação, como maiores DPP e menor área foliar especifica (AFE), condição observada no trabalho de Martins (2017). Entretanto, como os pastos se encontravam densos dentro da linha de plantio, é possível que os perfilhos recém-emergidos tenham sido sombreados pelos perfilhos remanescentes e que não senesceram (uma vez que não haviam sido decapitados), desencadeando o processo de autodesbaste (SBRISSIA et al., 2018).

Conforme a Tabela 3, o NFV e o IAF diferiram entre os tratamentos $(P<0,05)$, onde o número de folhas vivas por perfilho foi maior quando o rebaixamento do pasto foi realizado de forma intercalada, enquanto o maior IAF foi observado no rebaixamento constante de $40 \%$. Chaves et al. (2018) observaram número de folhas vivas semelhante ao presente trabalho, variando de 3,0 a 3,88 folhas/perfilho, entretanto não observaram diferença significativa entre os graus de severidade estudados. Sabendo que o processo de surgimento e morte de folhas segue o sincronismo de pastagens mantidas em equilíbrio, o número de folhas mantidas vivas para cada perfilho permanece constante em função da taxa de aparecimento e do tempo de vida de cada folha (LEMAIRE \& CHAPMAN, 1996).

É importante ressaltar que as con-

Tabela 3. Características estruturais do pasto submetido a diferentes manejos de desfolha Table 3. Structural characteristics of pasture under different defoliation management

\begin{tabular}{lcccccc}
\hline & \multicolumn{5}{c}{ Tratamentos } & \\
Variáveis & 40 & $40 / 70$ & $70 \mathrm{~F}$ & 701 & P-value $^{\#}$ & EPM \\
\hline CLF & 11,4 & 11,2 & 11,3 & 10,6 & 0,7450 & 0,6 \\
NFV & $3,1 \mathrm{C}$ & $3,9 \mathrm{~A}$ & $3,3 \mathrm{BC}$ & $3,5 \mathrm{~B}$ & $<0,0001$ & 0,1 \\
DPP & 3147 & 3103 & 3073 & 3036 & 0,7298 & 71,3 \\
IAF & $3,8 \mathrm{~A}$ & $2,0 \mathrm{~B}$ & $2,7 \mathrm{~B}$ & $2,3 \mathrm{~B}$ & 0,0072 & 0,3 \\
\hline
\end{tabular}

CLF - Comprimento Médio das Lâminas Foliares (cm/folha); NFV - Número de Folhas Vivas por perfilho; DPP - Densidade Populacional de Perfilhos (perfilhos $/ \mathrm{m}^{2}$ ); IAF - Índice de Área Foliar. \#Médias seguidas da mesma letra maiúscula na linha diferem pelo teste " $t$ " de Student $(P<0,05)$. 
dições climáticas foram adversas, com elevadas concentrações de chuvas após semeadura, atrasando a germinação e causando perda de estande, além de apresentar períodos longos de déficit hídrico que causaram a antecipação do término experimental. Talvez, com a avaliação de mais ciclos (i.e. cortes) poderia haver diferenças entre os tratamentos. Assim, a condução de ensaios em mais de um ano pode ser necessária, uma vez que as condições ambientais podem ser diferentes alterando o comportamento da cultura.

\section{Conclusão}

Dentro das condições aplicadas neste estudo, intervenções pontuais de alta severidade (70\%) não afetam a capacidade produtiva de pastos de azevém anual.

\section{Referências}

AMARAL, M.F.; MEZZALIRA, J.C.; BREMM, C., TRINDADE, J. K.; GIBB, M.J.; SUÑE, R.W.M.; CARVALHO, P.C.F. Sward structure management for a maximum short-term intake rate in annual ryegrass. Grass and Forage Science, v.68, p.271-277, 2012. DOI: https://doi. org/10.1111/j.1365-2494.2012.00898.x.

CARRÈRE, P.; LOUAULT, F.; SOUSSANA, J.F. Tissue turnover within grass clover mixed swards grazed by sheep. Methodology for calculating growth, senescence and in take fluxes. Journal of Applied Ecology, v.34, n.2, p. 333-348, 1997. DOI: https://doi. org/10.2307/2404880.

CAUDURO, G.F.; CARVALHO, P.C.F., BARBOSA, C.M.P., LUNARDI, R., NABINGER, C., SANTOS, D.T., VELLEDA, G.L. Fluxo de biomassa aérea em azevém anual manejado sob duas intensidades e dois métodos de pastejo. Revista Brasileira de Zootecnia, v.36, n.2, p.282-290, 2007. DOI: https://doi. org/10.1590/S1516-35982007000200003

CHAPMAN, D.F.; LEMAIRE, G. Morphogenetic and structural determinants of plants regrowth after defoliation. In: INTERNATIONAL GRASSLAND CONGRESS, 17., 1993, New Zealand. Proceedings[...] New Zealand, 1993. p.93-104.

CHAVES, D.R.; CÂNDIDO, M.J.D.; FURTADO,
R.N.; POMPEU; R.C.F.F.; MARANHÃO, T.D. Morfogênese de capim-canarana com duas frequências e duas intensidades de desfoIhação. Archivos de Zootecnia, v.67, n.259, p.396-402. 2018. Disponível em: https:// ainfo.cnptia.embrapa.br/digital/bitstream/ item/181724/1/cnpc-2018-Morfogenese. pdf. Acesso em: 10 jul. 2021.

COSTA, N.L.; JANK, L.; MAGALHÃES, J.A.; RODRIGUES, A.N.A.; BENDAHAN, A.B.; GIANLUPPI, V.; SANTOS, F.J.S. Acúmulo de forragem e características morfogênicas e estruturais de Megathyrsus maximus cv. Tamani sob intensidades de desfolhação. PUBVET, v.14, p.141, 2020. Disponível em: file://C:/Users/ Denise\%20Elejalde/Dropbox/My\%20PC\%20 (LAPTOP-65NOMLEC)/Downloads/caracteriacutesticas-morfogecircnica.pdf. Acesso em: 12 jul. 2021.

COSTA, C.M.; DIFANTE, G.S., COSTA, A.B.G.; GURGEL, A.L.C.; FERREIRA JR, M.A.; SANTOS, G.T. Grazing intensity as a management strategy in tropical grasses for beef cattle production: a meta-analysis. Animal, v.15, n.4, p.100192, 2021. DOI: https://doi. org/10.1016/j.animal.2021.100192.

EUCLIDES, V.P.; MONTAGNER, D.B; MACEDO, M.C.M.; DE ARAÚJO, A.R.; DIFANTE, G.S.; BARBOSA, R.A. Grazing intensity affects forage accumulation and persistence of Marandu palisadegrass in the Brazilian savannah. Grass and Forage Science, v.74, n.3, p.450-462, 2019. DOI: https://doi. org/10.1111/gfs.12422.

LEMAIRE, G.; CHAPMAN, D. Tissue flows in grazed plant communities. In: The ecology and management of grazing systems. Cab international. London: Hodgson, J. and Illius, A.W., 1996. p.3-36.

MARTINI, A.P.M.; BRONDANI, I.L.; SILVA, V.S.D.; ALVES, D.C.; MARTINI, P.M.; ARGENTA, F.M. Características morfogênicas e estruturais do sorgo forrageiro submetido a lotação contínua com novilhos de corte suplementados. Ciência Animal Brasileira, v.20, 2019. DOI: https://doi.org/10.1590/10896891v20e-45172.

MARTINS, C.D.M. Relações entre intensidades de desfolha e o potencial produtivo em pastos de capim-quicuiú, azevém anual e aveia preta. 2017.80 p. Tese (Doutorado) Universidade do Estado de Santa Catarina, Lages, 2017.

MEZZALIRA, J.C.; CARVALHO, P.C.D.F.;
FONSECA, L., BREMM, C., CANGIANO, C.; GONDA, H.L.; LACA, E.A. Behavioural mechanisms of intake rate by heifers grazing swards of contrasting structures. Applied Animal Behaviour Science, v.153, p.1-9, 2014. DOI: https://doi.org/10.1016/j.applanim.2013.12.014.

OLIVEIRA, A.B.; AURELIANO, J.V.P.; MATOS NETO, U.; CARVALHO, G.G.P.; VELOSO, C.M.; SILVA, F.F. Morfogênese do capim-tanzânia submetido a adubações e intensidades de corte. Revista Brasileira de Zootecnia, v.36, n.4, p.1006-1013, 2007. Disponível em: https://www.scielo.br/j/rbz/a/x6Bf5nNJXjhP bcd6HrGC6jy/?lang=pt. Acesso em: 10 jul. 2021.

PENA, K.S. NASCIMENTO JÚNIOR, D.; SILVA, S.C.; EUCLIDES, V.P.B.; ZANINE, A.M. Características morfogênicas, estruturais e acúmulo de forragem do capim-tanzânia submetido a duas alturas e três intervalos de corte. Revista Brasileira de Zootecnia, v.38, n.11, p.21272136, 2009. DOI: https://doi.org/10.1590/ S1516-35982009001100009

SANTOS, G. T.; ZANINI, G.D.; PADILHA, D.A.; SBRISSIA, A.F. A grazing height target to minimize tiller stem elongation rate in annual ryegrass swards. Ciência Rural, v.46, n.1, p.169-175, 2016. DOI: https://doi. org/10.1590/0103-8478cr20141508

SBRISSIA, A.F.; DUCHINI, P.G.; ZANINI, G.D.; SANTOS, G.T.; PADILHA, D.A.; SCHMITT, D. Defoliation strategies in pastures submitted to intermittent stocking method: underlying mechanisms buffering forage accumulation over a range of grazing heights. Crop Science, v.58, n.2, p.945-954, 2018. DOI: https:// doi.org/10.2135/cropsci2017.07.0447.

SBRISSIA, A.F.; DA SILVA, S.C. Tiller size/density compensation in marandu palisadegrass swards. Revista Brasileira de Zootecnia, v.7, n.1, p.35-47, 2008. Disponível em: https:// core.ac.uk/download/pdf/37447795.pdf. Acesso em: 15 de jul. 2021.

SCHMITT, D. Consumo de forragem por bovinos em pastos de capim-quicuiu sob lotação intermitente. 2016. 74f. Tese (Doutorado) - Universidade Estadual de Santa Catarina, Centro de Ciências Agroveterinárias, Lages, SC, 2016. Disponível em: https://www. udesc.br/arquivos/cav/id_cpmenu/1292/ daniel_schmitt_15671835000804_1292. pdf. Acesso em: 10 jul. 2021. 